\title{
LIBROS VENALES: LOS CATÁLOGOS DE VENTA DE LOS LIBREROS E IMPRESORES ANDALUCES (SIGLOS XVII-XVIII) $^{1}$
}

\author{
Pedro RUEDA RAMÍREZ \\ Departament de Biblioteconomia i Documentació. Universitat de \\ Barcelona
}

Recibido: 07/09/2012

Aceptado: 18/10/2012

RESUMEN: El artículo analiza doce catálogos de venta de libros impresos en Andalucía (cinco del siglo XVII y siete del siglo XVIIII). Hasta el momento conocíamos cinco catálogos, lo que ofrecía una imagen periférica del catálogo como herramienta de venta en las librerías andaluzas. Los nuevos catálogos localizados permiten ampliar perspectivas, al mostrar el papel de los libreros sevillanos en la publicación de catálogos para la venta en Nueva España (con cinco catálogos publicados entre 16801689). La venta en los territorios de la Corona española en América fue clave en las actividades de los libreros sevillanos y gaditanos, que utilizaron catálogos como medio de difundir los libros remitidos a Indias. Además se ofrece una panorámica de las librerías de Cádiz, Córdoba, Málaga y Granada que durante el siglo XVIII utilizaron catálogos como medios de venta de libros en el mercado andaluz y americano. El trabajo analiza catálogos de venta de surtido, de bibliotecas particulares o de fondos editoriales, el público al que se dirigen (venta a los lectores o al por mayor en resmas y docenas) y el grado de especialización de la oferta (libros únicamente en latín, inclusión de estampas "finas", etc.).

PALABRAS CLAVE: Librerías. Catálogos de venta. Consumo cultural. Libros. Lectura.

ABSTRACT: The article analyses twelve book catalogues printed in Andalusia, five dating from the seventeenth century and seven from the eighteenth. Until recently we knew of five catalogues, which offered us a limited idea of this means of promoting sales in Andalusian bookshops. The new catalogues allow us to broaden our perspective, as they throw further light on the role of booksellers from Seville in the publication of catalogues for New Spain, with five catalogues published between 1680 and 1689 . Sales in the territories of the Spanish Crown in America were an important source of income for booksellers from Seville and Cadiz, who used them as a means to publicize the books sent to the Indias. We also focus on the bookshops of Cadiz, Cordoba, Malaga and Granada which used catalogues as a means of selling books in the Andalusian and American markets during the eighteenth century. The study analyses catalogues of general book sales, private libraries or publisher's lists, and considers the target readership (sales to readers or wholesale in reams and dozens) and the degree of specialization of the offer (e.g., books only in Latin, inclusion of cards bearing religious images, and so on).

KEYWORDS: bookshops, sales catalogues, cultural consumption, books, reading.

${ }^{1}$ Este trabajo se inscribe dentro del Proyecto I+D+i "Censo de los catálogos españoles de venta de libros (de los orígenes a 1840)", Ref. HAR2009-08763, del Ministerio de Economía y Competitividad. 


\section{INTRODUCCIÓN}

Charon indicaba que los estudios sobre catálogos de libreros son raros y están dispersos y Kirsop llamaba la atención sobre el escaso interés prestado a los catálogos, prospectos, carteles, etc. ${ }^{2}$ Estas herramientas, poco conocidas más allá de los estudios bibliográficos y de historia de la literatura, son un referente clave en los estudios culturales, y constituyen una fuente de primer orden para el estudio de la circulación del libro y las redes de distribución ${ }^{3}$. En este trabajo ofreceremos resultados del censo que estamos reuniendo y elaboraremos una breve descripción de los ejemplares localizados. Es únicamente una primera lista de catálogos andaluces de la edad moderna que puede ofrecer pistas sobre las redes de libreros y librerías que utilizaron catálogos para distribuir los impresos ${ }^{4}$. En este trabajo nos referiremos a catálogos que constituyen una publicación independiente, con su paginación y signaturas propias, y quedarán excluidos los impresos al final de una obra, generalmente en las páginas que quedan libres en el último cuaderno y que formaron parte de la estructura del libro y del diseño editorial de la obra.

El interés por los catálogos fue constante entre los profesionales del libro, pero también entre coleccionistas y bibliotecarios, que contaron con el elenco de libros

${ }^{2}$ Charon, A. Lesage, C. Netchine, È. (2011). «Introduction». En Le livre entre le commerce et l'histoire des idées. Les catalogues de libraires (XVe-XIX siècle). Paris: École des Chartes, p. 7. KIRSOP, W. (1998). «The state of the discipline: booksellers and their customers: some reflections on recent research». Book History, 1, 1, pp. 283-303. Un análisis del contexto europeo en CoPPENS, C. (1999). «The Distribution of Books by Catalogue: printers' \& booksellers' catalogues until 1600». Discipline del libro. Bollettino della Facoltà di Lettere e Filosofia dell'Università degli Studi di Udine, 3 .

${ }^{3}$ Una aproximación, con pocas referencias a los territorios peninsulares, en SERRAI, A. (2005). «Bibliographie del commercio librario». En Profilo di storia de la bibliografia. Milano: Sylvestre Bonnard, pp. 202-212. Delgado CASAdo, J. (2003). «Los catálogos de libreros y editores». En Historia de la edición y de la lectura en España, 1475-1914. Madrid: Fundación Germán Sánchez Ruipérez, pp. 133-139.

${ }^{4}$ Un análisis detallado de las modalidades, que se ajusta al mercado anglo-norteamericano, en el estudio de MCKITTERICK, D. (1992). «Book catalogues: their varieties and uses». En P. DAvisON (ed.). The Book encompassed: studies in twentieth-century bibliography. Cambridge: Cambridge University Press, pp. 161-175. El análisis los catálogos en WinANS, R. B. (1978). «The beginnings of systematic bibliography in America up to 1800: further explorations». The Papers of the Bibliographical Society of America, 72, pp. 15-35. En el caso de Holanda ver VAN SELM, B. (1987). Een menighte treffelijcke boecken: nederlandse boekhandelscatalogi in het begin van de zeventiende eeuw. Ultrecht: HES; y el estudio de CRUZ, L. (2009). The Paradox of prosperity: the Leiden booksellers' guild and the distribution of books in early modern Europe. New Castle: Oak Knoll Press. En el caso portugués véase Domingos, M. D. (1992). «Os catálogos de livreiros como fontes da história do livro: o caso dos Reycend». En V Centenário do livro impresso en Portugal, 14871987. Lisboa, pp. 305-322. 
editados disponibles en el mercado. En las grandes bibliotecas los catálogos de libreros podían sumarse a las colecciones, ya que eran un instrumento bibliográfico que permitía rastrear ediciones y conocer la oferta. En una gran colección como la de El Escorial se conserva un volumen facticio con diversos catálogos de Lyon, entre ellos el Cathalogus librorum Lugduni, Parisiis, Italiae, Belgiae et Germaniae excussorum. Qui reperiuntur et venales habentur in aedibus Haeredum Gulielmi Rouillij (Lugduni: apud haeredes Gulielmi Rouillij, sub scuto Veneto, 1593) ${ }^{5}$. Algo parecido ocurre en las bibliotecas privadas. Juan Fernández de Velasco, Condestable de Castilla, reunió una de las más notables bibliotecas nobiliarias del reinado de Felipe II $^{6}$. En su biblioteca encontramos la recopilación de los libros puestos a la venta en la feria de Fráncfort que elaboró Georg Willer titulada Collectio in vnum corpus omnium librorum Hebraeorum, Graecorum, Latinorum necnon Germanice, Italice, Gallicè, \& Hispanicè scriptorum, qui in nundinis Francofurtensibus ab anno 1564 vsque ad Nundinas autumnales anni 1592 (Francofurti: ex officina typographica Nicolai Bassaei, 1592) ${ }^{7}$.

Un complemento importante de los catálogos fueron los carteles de venta, de los que conservamos escasos ejemplos, y los anuncios en la prensa ${ }^{8}$. En el siglo XVIII las publicaciones periódicas comenzaron a recoger las noticias de nuevos libros y se inició la edición de reseñas en revistas literarias. ${ }^{9}$ Las gacetas publicadas contenían anuncios de los nuevos libros a la venta en casas de particulares,

${ }^{5}$ Morisse, G. (2003). «Les circuits de difusión du livre en Espagne au XVI ${ }^{\mathrm{e}}$ siècle». En ANDrÉANi, R. Michel, H. y PÉlaquier, E. (eds). Des moulins à papier aux bibliothèques: le livre dans la France méridionale et l'Europe méditerranéenne: $X V I^{e}-X X^{e}$ siècles: actes du colloque tenu les 26 et 27 mars 1999 à l'Université Montpellier III. Montpellier: Université Paul-Valéry Montpellier III, t. I, p. 231.

${ }^{6}$ FERNÁNDEZ POMAR, J. M. (1967). «Manuscritos del VI condestable de Castilla en la Biblioteca Nacional». Helmantica, 18, pp. 89-108. Más recientemente LóPEZ-VIDRIERO, M ${ }^{a}$ L. (2008). «Encomio y gloria: brillo imperial del Milanesado en los libros italianos de las colecciones de Frías y Gondomar». En EGIDO, A. y José Enrique Laplana (eds.). Mecenazgo y humanidades en tiempos de Lastanosa. Homenaje a Domingo Ynduráin. Zaragoza: Instituto de Estudios Altoaragoneses, Institución «Fernando el Católico», pp. 325-448.

${ }^{7}$ Archivo Histórico de Protocolos de Madrid, leg. 24850, f. 350r.

${ }^{8}$ Otros medios de publicidad del libro fueron tablas con listas manuscritas de libros a la venta o los propios escaparates. Véase el estudio de CALAME, C. (2006). «Une affiche publicitaire au XVIII ${ }^{\mathrm{e}}$ siècle: les volets de la librairie Girardet». Histoire et civilisation du livre: revue internationale, 2, pp. 189-212.

${ }^{9}$ MORÁn OrTí, M. (2001). «El libro religioso durante la crisis del antiguo régimen. Un estudio cuantitativo a través del Diario de Madrid». Hispania Sacra, 18, 107, pp. 133-148. Y la síntesis MorÁn ORTí, M. (2011). Editores, libreros e impresores en el umbral del Nuevo Régimen. Madrid: Consejo Superior de Investigaciones Científicas. 
conventos, tiendas o librerías, por ejemplo, en la Gaceta de México (1735) se anunciaba la venta en un colegio de "una quartilla del modo de contar los antiguos y de jugar a pares y nones por los dedos y otra explicación pythagórica de la Y". Este último título se refiere a la $Y$ de Pitágoras, que alude a la tradición que le atribuía su origen a Pitágoras de Samos. Era un texto rescatado en el Renacimiento que moralizaba, en una alegoría de la letra i griega, los dos caminos que podía seguir el hombre: el del vicio y el de la virtud. Cada asta de la letra ofrecía una ruta bifurcada, con lo que se aludía al buen y el mal camino que podía seguir el hombre y que le encaminaría al cielo o al infierno ${ }^{10}$.

Esta necesidad de información sobre nuevos libros tuvo una interesante consecuencia, generó un amplio discurso sobre la proliferación de los libros, y tuvo como consecuencia la aparición de herramientas bibliográficas para ordenar el creciente universo editorial europeo. Tal como afirmaba Villanueba "mientras subsista el mundo, habrá necesidad de nuevos libros, acomodados a las nuevas generaciones de los hombres" ". Villanueba conocía bien la afición por la escritura de su tiempo y la curiosidad intelectual (y el beneficio editorial) que favoreció la producción de nuevos textos. Esta proliferación generó la necesidad de bibliografías, realizadas por eruditos o letrados, pero también por libreros como Guillaume-François Debure (1732-1782), que había publicado una exitosa Bibliographie instructive (1763-1768), o François Los-Rios, un librero de Lyon que publicaría la Bibliographie instructive ou Notice de quelques livres rares, singuliers \& difficiles à trouver $(1777)^{12}$. A estos libros se sumarían durante el siglo XVIII la proliferación de noticias y avisos sobre libros en la prensa, que permitieran conocer los mejores textos y seleccionar los que resultaban más adecuados para incrementar las bibliotecas. En los Estatutos y Ordenanzas del Real Colegio de Cirugía de la Armada de Cádiz, de 1764, se advertía de la misión del bibliotecario de "adquirir noticia [...] de las obras que salen de nuevo, que se anuncian, o se extractan en los Diarios" $"$.

Antonio Rodríguez-Moñino publicó un pequeño librito sobre Catálogos de libreros españoles: 1661-1798: intento bibliográfico (1942) en el que recogía las

${ }^{10}$ BouzA, F. (1991). «Vida moral del alfabeto. El canónigo Antonio de Honcala y la letra de Pitágoras». Fragmentos, 17-18-19, pp. 16-29.

${ }^{11}$ Villanueba, J. L. (1807). El kempis de los literatos. Madrid: en la imprenta Real, p. 256.

12 Bouge-Grandon, D. (2001). «Enseigner les livres: le témoignage de François de Los-Rios». Revue française d'histoire du livre, 106-109, pp. 119-132.

13 Gestido Del Olmo, R. (2009). «Huellas del Real Colegio de Cirugía de Cádiz en la Biblioteca de la Universidad». En Estudios superiores en Cádiz desde 1748: Armada e Ilustración. Madrid: Publicaciones de Defensa; Cádiz: Universidad, p. 151. 
fichas de los catálogos de venta. Fue un trabajo pionero en España. Esta primera gavilla de erudición resultó insuficiente e incompleta. El autor amplió de manera notable la cronología y las entradas, llegando a 161 registros, en su Catálogos de libreros españoles (1661-1840): intento bibliográfico (1945). El tesón y los viajes de investigación le permitieron ampliar el texto con más noticias, y finalmente publicar una Historia de los catálogos de librería españoles (1661-1840): estudio bibliográfico (1966) con 196 entradas $^{14}$. Este último libro es el que suele citarse como referencia, pero la génesis de sus trabajos permite rastrear el interés por estos efímeros materiales, difíciles de rastrear y conseguir, durante 24 años. RodríguezMoñino, bibliógrafo y coleccionista tenaz ${ }^{15}$, fue capaz de detectar el valor que podían tener estos modestos catálogos para seguir la pista a las ediciones, reconstruir colecciones dispersas y conocer de primera mano la labor editorial y de distribución de los impresores y libreros ${ }^{16}$.

En su Historia de los catálogos de librería españoles hay algunas referencias a libreros andaluces. El fino olfato bibliográfico de Rodríguez-Moñino le hizo sospechar que sería posible localizar más catálogos, ya que "con rebuscas a fondo en los depósitos del Estado han de acrecentarse mucho estas simples notas"17. Como en tantos otros casos iba bien encaminado y hemos podido verificar la existencia de más catálogos de libreros andaluces durante la investigación desarrollada en el proyecto "Censo de los catálogos españoles de venta de libros (de los orígenes a 1840)"18.

14 Rodríguez MoÑino, A. Catálogos de libreros españoles, 1661-1798: intento bibliográfico. Madrid: Tip. de los Sucesores de J. Sánchez Ocaña, 1942. Catálogos de libreros españoles, 16611840: intento bibliográfico. Madrid, 1945. Historia de los catálogos de librería españoles (16611840): estudio bibliográfico. Madrid, 1966.

${ }^{15}$ El contexto vital de estos años en la biografía de RODRíGUEZ-MOÑINO SORIANO, R. (2002). La vida y la obra del bibliófilo y bibliógrafo extremeño D. Antonio Rodríguez-Moñino. Madrid: Beturia. También en Bernal Salgado, J. L. (2010). Antonio Rodríguez-Moñino, un extremeño universal. Badajoz: Editora Regional de Extremadura.

${ }^{16} \mathrm{El}$ interés por este tipo de materiales en la historiografía anglonorteamericana se inició ya en el siglo XIX, y ha generado una amplia y riquísima historiografía, una reunión de ensayos en esta línea en Myers, R. Harris, M. MANDelbrote, G. (eds.) (2009). Books for sale: the advertising and promotion of print since the fifteenth century. New Castle: Oak Knoll Press; London: British Library. La bibliografia queda recogida en HowARD-HILL, T.H. (2009). The British book trade, 1475-1890: a bibliography. New Castle, Delaware: Oak Knoll Press; London: The British Library.

${ }^{17}$ RodríGUEZ-MoÑINO (1966). Op. cit. También se ha interesado por estos catálogos FERNÁNDEZ SÁNCHEZ, J. (1994). Historia de la bibliografía en España. Madrid: Compañía Literaria.

${ }^{18} \mathrm{http}: / /$ cataloguslibrorum.wordpress.com/ 


\section{LOS CATÁLOGOS IMPRESOS EN ANDALUCÍA}

La resma de casos es corta, apenas doce catálogos, incluyendo algunos detectados en fuentes indirectas o sin referencias actuales de ejemplares. De ellos Rodríguez-Moñino recogía cinco ${ }^{19}$. El incremento ha sido posible gracias a las pesquisas desarrolladas en México, ya que sus archivos y bibliotecas conservan catálogos de venta sevillanos y gaditanos destinados al abastecimiento del virreinato de Nueva España. Este aspecto, en el que insistiremos, es un hecho diferencial respecto a otros catálogos europeos, destinados a las ferias comerciales de libros alemanas, a la venta de libros de bibliotecas particulares en subasta pública y al abastecimiento de mercados locales o regionales mediante la venta de surtidos $^{20}$. Los catálogos andaluces tuvieron como finalidad dar a conocer la oferta de libros de las tiendas para el mercado de Andalucía y del otro lado del Atlántico, estableciendo unos interesantes vínculos entre las dos orillas, ya que estos catálogos revelan lecturas comunes e intereses compartidos. Es muy probable que nuevas pesquisas en los archivos permitan localizar otros catálogos, y conviene recordar la más que probable pérdida de muchas ediciones. Al respecto el caso del librero francés Antoine Jombert (1712-1784) es revelador, de los 25 catálogos que publicó se han conservado ejemplares únicamente de 20 de ellos ${ }^{21}$.

Los doce catálogos se distribuyen de la siguiente manera. En Sevilla se imprimieron cinco catálogos, ligados a los negocios de la trama del librero e impresor Tomás López de Haro, entre los años 1680 y 1689, lo que resulta indicativo del peso de las librerías sevillanas en estos momentos. Los otros siete catálogos analizados son del siglo XVIII, pero tuvieron una distribución territorial muy diferente, ya que se editaron tres en Cádiz, dos en Málaga, uno en Córdoba y uno sin pie de imprenta. De estos casos se ha logrado localizar ejemplares de ocho catálogos, pero los otros cuatro se conocen por referencias, sin que haya sido posible, por ahora, encontrar ejemplares. Lo más probable es que otros muchos hayan desaparecido, sin dejar rastro. La diversificación de centros editores de catálogos en el siglo XVIII resulta reveladora de una cierta activación del negocio

${ }^{19}$ RodrígueZ-Moñino (1966). Op. cit., nos. 3, 42, 79, 85 y 86.

${ }^{20}$ Catalogi nundinales, 1571-1852: die Frankfurter und Leipziger Messkataloge der Herzog August Bibliothek, Wolfenbuittel, zusammengestellt von Wolfgang Borm. Wolfenbüttel: Die Bibliothek, 1982. LEAVEN, A.H. (1992). «The Frankfurt and Leipzig book fairs and the history of the Dutch book trade in the seventeenth and eighteenth centuries». En Le magasin de l'univers: the Dutch republic as the centre of the European book trade. Leiden: E. J. Brill, pp. 185-197. GRUYS, J. A. KOOKER, H. W. De (1997). Book sales catalogues of the Dutch Republic, 1599-1800. Leiden: IDC.

21 SARrazin, V. (2006). «Introduction». En Catalogues de libraires: 1473-1810. Paris: Bibliothèque nationale de France, p. 18. 
de venta por catálogo, especialmente en la segunda mitad del siglo XVIII, ya que de los siete catálogos de esta centuria, resulta que los tres gaditanos se concentran en los años 1760-1769, y los tres de Málaga y Córdoba son de finales del XVIII. En este sentido los catálogos coinciden con un incremento de la producción nacional y, lo que más nos interesa ahora, una utilización creciente de la publicidad en la difusión de las obras. La Gaceta de Madrid publicaba, en los años 1761-1783, una media anual de 309 anuncios de libros, pero unos años después, en 1791-1807, la media anual era de 1.301. Tal como apunta Buiguès "la tendencia general es la de un aumento constante"22.

Aunque no todos valoraron por igual esta proliferación de libros, y el hecho de contar con librerías surtidas no era, por sí mismo, suficiente para generar un negocio redondo. Los catálogos junto a otras estrategias fueron uno de los medios para mejorar las ventas, ya que las tiendas se transformaron lentamente y los libreros lograron modernizar sus tácticas publicitarias abriendo nuevas vías, aunque el éxito no siempre estaba asegurado. Las quejas de algunos libreros que aparecen como personajes literarios dan buena cuenta de los riesgos de su oficio. En una de sus visiones Torres Villarroel entró en una librería, en ella encontró a un librero que le contó como: "estas tiendas hervían antes de todo género de personas, vendíanse los libros, continuabase el comercio, hoy se nos sale la vida por los agujeros de la hambre. ¡Mal haya la edad tan bruta! ¡Siglo irracional!”23.

\section{SEVILLA, 1680-1689}

El primer catálogo publicado en Andalucía que conocemos lleva por título Catalogus librorum, o memoria de libros de todo genero de facultades, que se venden en casa de Diego Cranze en esta ciudad ([Sevilla]: Por Diego Cranze, $1680)^{24}$. En la portada un pequeño grabado xilográfico muestra a las mártires Santa

22 Buiguès, Jean-Marc (2011). «Los anuncios de impresos poéticos en la Gaceta de Madrid (1697-1750)». Bulletin Hispanique, 113, 1, pp. 331-366.

23 Torres Villarroel, D. DE (1794). Sueños morales, visiones y visitas con D. Francisco de Quevedo por Madrid, Barca de Aqueronte y residencia infernal de Pluton, trasladolos desde la fantasia al papel el Dr. D. Diego de Torres Villarroel ... tomo II. Madrid: en la Imprenta de la Viuda de Ibarra, p. 19. El siglo "irracional" o ilustrado, según se mire, favorecería la difusión de los textos de manera notable, logrando públicos diversificados y espacios de sociabilidad como las tertulias que permitieron el debate sobre libros e ideas, como pone de manifiesto el caso analizado por CANTOS CASENAVE, M. (2009). «Entre la tertulia y la imprenta, la palabra encendida de una patriota andaluza: Frasquita Larrea (1775-1838)». En CASTELlS, I. (coord.). Heroínas y patriotas: mujeres de 1808. Madrid: Cátedra, pp. 269-294.

${ }^{24}$ El bibliotecario e investigador Kenneth Ward tuvo la generosidad de compartir el hallazgo de este catálogo. México, D.F. Archivo General de la Nación (AGN). Inquisición, vol. 667, f. 348r-352r. 
Justa y Santa Rufina a los lados de la Giralda, una alegoría de su papel protector del edificio catedralicio en el terremoto de 1504. Este catálogo era muy modesto tipográficamente. Fue impreso de una manera un tanto descuidada, ya que abundaban las erratas y repeticiones en las más de seiscientas entradas de títulos que se anotan, como ocurre con "Boethij de Consolatione" que aparece en dos ocasiones, en referencia a la Consolación de la filosofía de Boecio, su texto más famoso y apreciado. O la entrada "Lara de Vitis [i.e. vitae] hominis" que puede cambiar el sentido al contenido que podría esperarse del texto, en este caso uno de los libros de Alonso Pérez de Lara, el texto jurídico Compendium vitae hominis in iure fori et poli, vsque ad perfectam aetatem et senectam (editado en Lyon, 1672).

Diego Crancer (también aparece en la documentación como Cranser, Cranssen, Crance, Cranze o Crançe) aparecía en el pie de imprenta del catálogo, pero además viajó a América para vender los libros que contenía. En 1680 llegó a Puebla de los Ángeles con un importante cargamento de libros y se puso en contacto con el comisario inquisitorial Francisco Flores de Valdés. El librero le entregó la licencia de pase que había obtenido en Sevilla y el comisario no tuvo inconveniente en comprarle algún libro, retener otros que le parecían sospechosos y, lo más importante para Crancer, el comisario le permitió que "abriese los cajones de libros y vendiese" en Puebla de los Ángeles, la segunda ciudad en importancia en el territorio virreinal mexicano ${ }^{25}$. Un local de ocasión fue más que suficiente para que Crancer pudiera vender a los letrados poblanos una excelente colección de textos académicos provenientes de las mejores prensas europeas. El asunto de todos modos no resultó demasiado bien, ya que entre los libros que llegaron había numerosos sin expurgar, de hecho no se habían tachado a tinta los párrafos que debían eliminarse según lo establecían los índices inquisitoriales publicados por el Santo Oficio. El comisario advirtió a los inquisidores mexicanos sobre este librero que según tenía entendido "es extranjero", lo que lo convertía en sospechoso. Además, un cuñado suyo era librero en Sevilla. En esto el comisario acertó, ya que el librero sevillano Tomás López de Haro se había casado en Sevilla con Manuela Crancer, de origen flamenco, y hermana de Diego Crancer. ${ }^{26}$ La carta del comisario advertía que Crancer dirigía sus pasos a México "a vender los libros que le han

25 Rueda RAmíREZ, P. (2012). «Libreros y librerías poblanas: la oferta cultural en el mundo moderno». En GARONE Gravier, M. (ed.). Miradas a la cultura del libro en Puebla: bibliotecas, tipógrafos, grabadores, libreros y ediciones en la época colonial. México: Ediciones de Educación y Cultura. Instituto de Investigaciones Bibliotecológicas, UNAM, pp. 377-400.

${ }^{26}$ Archivo Histórico Provincial de Sevilla (AHPSe). Protocolos, leg. 12985 (oficio 19), fol. 656rV. 
quedado y va llenando este reino de libros prohibidos"27. En Puebla consiguió una buena clientela y la colaboración inicial del comisario, pero era cuidadosamente vigilado en sus movimientos y sus libros escudriñados por el ojo pesquisidor de los lectores. Algunos de los que compraron sus libros, lo denunciaron. El bachiller Carlos García Durango le compró un libro en el que encontró citados a Lutero y Calvino y lo denunció, pidiendo, además, que "Diego Crancer, librero, me vuelva la cantidad de pesos que le dí" ${ }^{28}$. Eran riesgos que los libreros intentaron minimizar. Crancer no volvió a negociar con libros directamente en Nueva España. En los años siguientes tomó el relevo Tomás López de Haro, pero utilizó a factores e intermediarios de la Carrera de Indias para distribuir los libros en México, sin poner en riesgo a los miembros de su familia.

Tomás López de Haro estuvo en activo como impresor en la ciudad de Sevilla entre 1678 y 1693, publicando un considerable número de títulos, algunos de ellos vinculados al mundo americano. En 1684 se imprimió en su taller el Arte y gramática general de la lengua de Chile de Luis de Valdivia, aunque su imprenta es conocida por la edición de las Obras (1692) de la poetisa mexicana Sor Juana Inés de la Cruz. Desde Sevilla participaba con regularidad en el tráfico de libros con América, además en 1682 y 1683 publicó dos catálogos de venta de libros. El Catálogo, o memoria de libros, de todas facultades (Sevilla, 1682) tenía más de seiscientas entradas de títulos de libros, a los que hay que sumar una lista de 124 títulos de comedias sueltas que vendía por docenas ${ }^{29}$. Este catálogo fue seguido, al año siguiente por un suplemento denominado Catalogo segundo, o memoria de libros de todas facultades (Sevilla, 1683). En la portada, bien visible, se indica que los libros "se venden en casa del capitán Fernando Romero", lo que nos da una pista importante, ya que este capitán llevó el catálogo a Nueva España, embarcó los libros y los puso a la venta en el puerto de Veracruz.

El capitán Romero estuvo estrechamente ligado a los negocios del librero Tomás López de Haro, que fue su fiador en diversos negocios, y participó activamente en la comercialización de libros en la Carrera de Indias. En 1682, el mismo año de publicación de uno de los catálogos, viajó a Nueva España y se declaró deudor de 2.600 pesos de a ocho reales de plata "sobre veinte y siete

${ }^{27}$ AGN. Inquisición, vol. 667, f. 348r-352r.

${ }^{28}$ AGN. Inquisición, vol. 667, f. 348r-352r.

${ }^{29}$ Es una de las primeras listas de este tipo conocidas para el siglo XVII. La proliferación de comedias sueltas en las imprentas sevillanas y el papel que jugaron para el público durante dos centurias en LÓPEZ, F. (1996). «La comedia suelta y compañía, "mercadería vendible" y teatro para leer». En Sala Valldaura, J. M. (ed.). El teatro español del siglo XVIII. Lleida: Universitat de Lleida, vol. II, pp. 589-604. 
caxones de libros desde número dies y siete a quarenta y tres y sobre un paquete de dichos libros número quarenta y quatro marcados con la del margen que yo el dicho Fernando Romero lleuo cargados de mi quenta en la nao nombrada Nuestra Señora del Carmen"30. Además de negociar con libros Romero tuvo numerosas actividades de compra-venta, en 1687 se obligaba a pagar 350 escudos a Simón Rodríguez por "veynte mazos de cinquenta libras cada uno de hilo de vela y seis varilillos [i.e. barrilillos] de mercerías números uno hasta seis ... embarcados en el navío nombrado Santa Cruz de Carauaca"31.

Figura 1: Catalogo segundo, o memoria de libros de todas facultades (Sevilla, 1683)

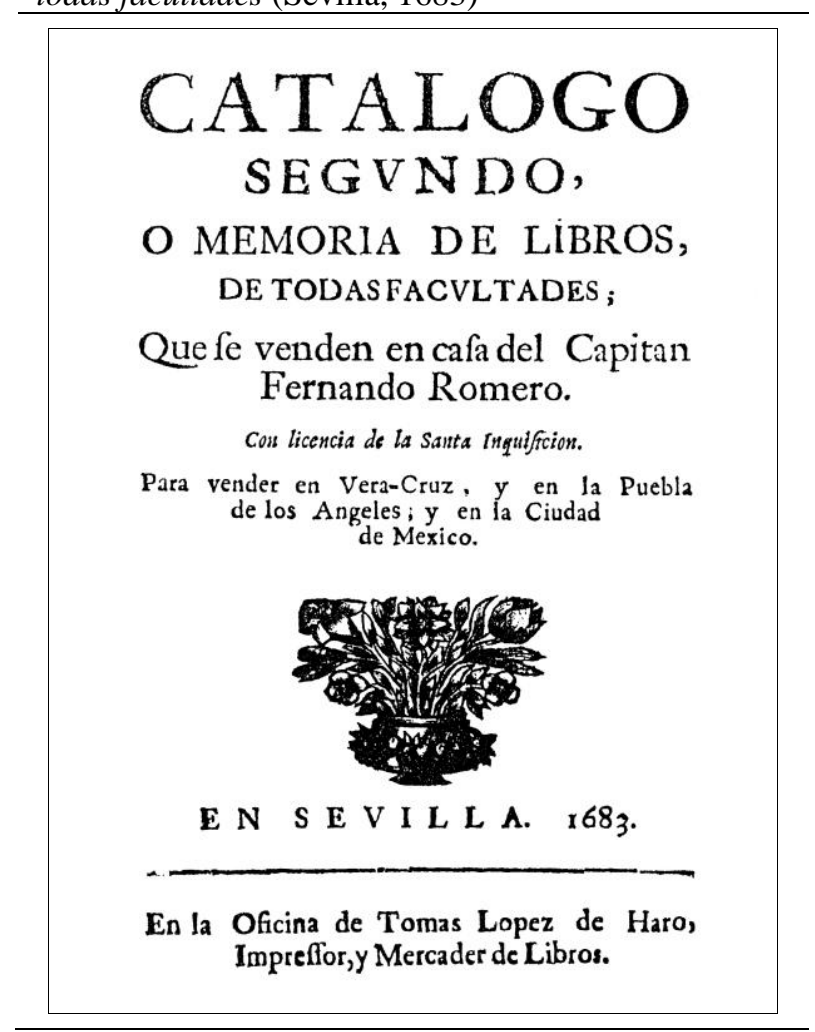

El siguiente catálogo llevaba por título Catalogo, o Memoria de libros, de todas

${ }^{30}$ AHPSe. Protocolos, leg. 3741 (oficio 5), fol. 694r-v.
${ }^{31}$ AHPSe. Protocolos, leg. 5139 (oficio 7), fol. 241r-v. 
facvltades (En Sevilla: Por Thomas Lopez de Haro, Impressor, y Mercader de Libros, en las siete Rebueltas, junto a la Imagen, año 1687) ${ }^{32}$. En la portada se indicaba que los libros "se venden en casa del Capitán D. Fernando Romero", con lo que volvemos a encontrarnos al mismo intermediario de los catálogos de 1682 y 1683, y que se pusieron a la venta "con licencia del Tribunal de la Santa Inquisición”, lo que intentaba, como podemos imaginar, salvar cualquier posible perspicacia de los compradores, que podían de este modo comprar sin cargo de conciencia y disfrutar de los tomos. En todo caso, esta licencia, concedida en Sevilla para el pase de los libros, no era una total garantía. Es interesante constatar la ruta de venta, que se anota igualmente en la portada del catálogo, ya que se indica que los libros son "para vender en la Vera-Cruz, en la Puebla de los Ángeles, y en la Ciudad de México". El 22 de mayo de 1687 Fernando Romero presentó una hoja de registro para cargar en el navío Santa Cruz "veinte cajoncillos de libros de números 1 a 20" que debían entregársele "en el puerto de la Veracruz en primer lugar a sí mismo"33. En la hoja de registro no se hace mención de Tomás López de Haro, ni se presenta la lista de títulos, pero fueron, probablemente, los títulos que constaban en el catálogo.

El último catálogo conocido del siglo XVII apareció con el título de Catalogo, o memoria de todas facultades pero sin pie de imprenta, aunque es bastante probable que se publicara en torno a 1689 en Sevilla. En la portada se indica que los libros "se venden en casa del capitán Diego Ibáñez"34. En 1678 este vecino de Sevilla se estaba preparando para viajar con los galeones de Tierra Firme, entonces tenía 29 años y mostraba una "señal de herida de en medio de la frente" 35 , algunos años más tarde, en 1684 volvía a realizar el viaje atlántico obteniendo de la Casa de la Contratación "despacho de embarcación [...] para cualquiera navío de la flota de Tierra Firme" ${ }^{\text {"3 }}$. En su viaje a Nueva España de 1689 debía contar con unos cuarenta años y una dilatada experiencia en la Carrera de Indias. Diego Ibáñez de

32 AGN. Inquisición,1086, exp. 11, f. 254r-263r. Quiero agradecer la generosidad de Idalia García, del Cuib de la UnAM, que amablemente me ha proporcionado información sobre este catálogo. El contexto inquisitorial en NESVIG, M. A. (2006). «"Heretical plagues" and censorhip cordons: colonial Mexico and the transatlantic book trade». The American Society of Church History, 75, 1, pp. 1-37; y en RAMOS SORIANO, J. A. (2011). Los delicuentes de papel. Inquisición y libros en la Nueva España (1571-1820). México: Instituto Nacional de Antropología e Historia; FCE.

${ }_{33}$ Archivo General de Indias (AGI). Contratación, 1243. Santa Cruz, f. 50r.

34 Torre Revello, J. (1929). «Un catálogo impreso de libros para vender en las Indias Occidentales en el siglo XVII». Boletín del Instituto de Investigaciones Históricas, VII, 40, pp. 233253.

${ }^{35}$ AGI. Contratación, 5442, N.12, f. 2r.

${ }^{36}$ AGI. Contratación, 5446, N. 2, f. 2 r. 
Guevara figuraba como maestre de uno de los navíos de la flota del marqués del Vado del Maestre, que salió a Tierra Firme en $1690^{37}$. La venta de libros resultó, sin duda, uno más de los numerosos negocios de los que era factor. El 10 de enero de 1690 Manuela Crancer, la esposa de Tomás López de Haro, cargaba en el navío Nuestra Señora de Atocha "doce cajoncitos de libros" ${ }^{38}$ y en el navío Nuestra Señora del Carmen "diez cajones de libros"39. Estos 22 cajones debían entregarse al capitán Diego Ibáñez de Guevara en Veracruz. Es bastante probable que estos sean los cajones de libros que contenían los títulos anotados en el catálogo de 1689. Este catálogo presentaba una estructura por lengua y formatos, comenzando con los "libros de a folio en latín en general", seguidos de los "a folio en romance en general", de formato cuarto y los de "de octavo, y pequeños, en latín y romance" con 369 entradas, además de "dozenas de comedias de Madrid" y "resmas de estampas ordinarias". La venta por docenas de las comedias sugiere la incorporación de comedias sueltas, tal como ocurrió en los catálogos de 1682 y 1683.

Los cinco catálogos impresos en Sevilla tuvieron como finalidad la venta en Nueva España, un aspecto original e innovador, protagonizado por Tomás López de Haro y sus factores. Fueron los primeros catálogos publicados en Andalucía y estuvieron ligados a la Carrera de Indias. El tráfico de libros a los territorios americanos resultó atractivo para los libreros andaluces desde el inicio de la Carrera de Indias ${ }^{40}$. De hecho, en su conjunto revelan un mercado del libro muy activo, ligado a una de las redes más innovadoras del momento en Sevilla. Tomás López de Haro fue capaz de desarrollar sus negocios en un momento etiquetado por la historiografía como de "crisis". A la novedad de la publicación del catálogo se sumaría la transferencia de un abanico de textos variado, incluyendo numerosas obras científicas, abundantes obras teatrales y una notable diversidad de textos devotos y de humanidades.

\section{CÁDIZ, 1760-1769}

El mercader de libros e impresor Manuel Espinosa de los Monteros (1713-1781) remitió a Indias 212 cajones de libros entre 1750 y 1778, siendo uno de los

${ }^{37}$ AGI. Contratación, 1247, N.10.

38 AGI. Contratación, 1247. Nuestra Señora de Atocha, f. 82.

${ }^{39}$ AGI. Contratación, 1247. Nuestra Señora del Carmen, f. 55.

${ }^{40}$ GONZÁLEZ SÁNCHEZ, C. A. (2011). New world literacy: writing and culture across the Atlantic, 1500-1700. Lewisburg: Bucknell University Press. GonZÁLEZ SÁNCHEZ, C. A. (2008). Atlantes de papel. Adoctrinamiento, creación y tipografía en la Monarquía Hispánica de los siglos XVI y XVII. [Barcelona]: Rubeo. 
mercaderes de libros más activos en el comercio con México ${ }^{41}$. En 1760 imprimió un extenso catálogo de venta de libros con el título de Catalogo de los libros, que se hallaran en la libreria de Dn. Manuel Espinosa de los Monteros, Impressor Rl. de Marina, en la ciudad de Cadiz, calle de S. Francisco ([Cádiz], 1760). En este impreso de 118 páginas difundió la oferta de surtido de libros en latín, sin indicar los precios y con unas descripciones breves (autor, título, formato, volúmenes). Este catálogo de 1760 no aparece recogido en el trabajo de Rodríguez-Moñino, que dio a conocer el Catalogo de libros, que se venderàn en Cadiz en los meses de agosto, y septiembre de 1769. en la librería de don Francisco de Rioja, frente de la Iglesia de la Candelaria. En el caso de Rioja todo parece indicar que se trataba de una liquidación de bibliotecas particulares o una venta de un fondo con determinadas condiciones, ya que los compradores tenían fijado en un plazo de compra de dos meses. Rioja iniciaba el catálogo con los libros "raros" y a continuación los de "de impresiones antiguas en los primeros años de la imprenta", diccionarios o libros en griego y hebreo ${ }^{42}$. Como veremos una distribución muy distinta a la de Manuel Espinosa de los Monteros y a la de los otros catálogos.

Manuel Espinosa de los Monteros iniciaba su catálogo con un texto de notable interés al indicar al "lector benévolo" las intenciones del volumen. El librero adopta el rol de un autor en la captatio benevolentia, aunque en realidad está anunciando su mercancía, al indicar al futuro comprador que "este catálogo que te ofrezco es de los libros que al presente tengo", pero advierte que para los otros impresos de erudición "puedes con toda seguridad ocurrir a esta mi casa en la Oficina de la Imprenta Real de Marina en Cádiz, que en breve te serviré". ${ }^{43}$ Los pies de imprenta de sus libros manifiestan este título, por ejemplo, en el Tratado instructivo y practico de mani-obras navales para el uso de los cavalleros guardias-marinas (1766) de Santiago Agustín de Zuloaga figura como "Impressor Real de Marina (por S.M.)", lo que le otorgaba un estatus de servicio y fidelidad a la Corona, sin olvidar la familiaridad con la élite militar que se estaba formando en la ciudad ${ }^{44}$. Además Espinosa destacaba que tenía "facilidad de recebirlos así de

41 Gómez Álvarez, C. (2011). Navegar con libros. El comercio de libros entre España y Nueva España. Una visión cultural de la Independencia (1750-1820). Madrid: Trama editorial, 2011, pp. 6768.

42 Madrid. Biblioteca Lázaro Galdiano, M 1-2-30(12). El papel de los catálogos en las ventas de libros usados en GoINGA, H. Van (1994). «The long life of the book: public book auctions in Leiden, 1725-1805, and the second-hand book trade». Quarendo, 24, 4, pp. 243-274.

${ }^{43}$ Catalogo de los libros, que se hallaran en la libreria de Dn. Manuel Espinosa de los Monteros. [Cádiz], 1760, A2r.

44 ZULOAGA, S. A. de (1766). Tratado instructivo, y practico de mani-obras navales para el uso de los cavalleros guardias-marinas. En Cadiz: Por D. Manuel Espinosa de los Monteros. 
nuestra España, como de las ciudades extranjeras"45. El abastecimiento de libros extranjeros fue constante en el mercado del libro español. Fueron varios los libreros-editores que publicaron libros en castellano o en latín de autores españoles y vendieron obras, tanto a libreros como a particulares, destinados al mercado ibérico y latinoamericano, como los Verdussen, que llegaron a editar catálogos de venta que fueron, sin duda, una herramienta clave de su estrategia junto a los agentes que tenían en Madrid, como era el caso de Florian Anisson ${ }^{46}$.

En este preliminar ofrecía sus prensas "si quisieres imprimir alguna obra tuya, o agena", indicando que su taller tenía abundancia de tipos de imprenta para hacerlo "en buena letra, que tengo de todas clases, y mandadas hacer distintas fundiciones de una fábrica moderna, que florece hoy con la mayor estimación, y crédito en la ciudad de Barcelona" 47 . Esta "fábrica moderna" debe hacer alusión a la fundición de punzones, matrices y tipos de Josep Eudald Marian Pradell (1721-1788), un hijo de un armero de Ripoll que se instaló en Barcelona en 1741. En 1758 dio a conocer un primer catálogo de los tipos que elaboraba con la colaboración, como fundidor, del impresor Felio Pons. El éxito de Pradell le llevaría a conseguir una pensión real en 1764, trasladándose a Madrid ${ }^{48}$. El Catálogo de 1760 encaja, justamente, en el momento de mayor difusión de los tipos de Pradell, además la alusión a la "fábrica moderna" por parte de Espinosa de los Monteros coincide con la referencia a la "fábrica de nueva letra" con la que inicia su catálogo de tipos de letra el "maestro armero" Pradell en 1758.

Impressor Real de Marina (por S.M.). El ejemplar que manejamos indica que era "para el uso del theniente de fragata Dn Joseph Zur[ita]". Biblioteca Pública de Cádiz, XVIII-314. El contexto gaditano es analizado magistralmente por GARCíA-BAQUERO GONZÁLEZ, A. (2006). «Una ciudad abocada al mar: comercio y sociedad mercantil en el Cádiz del siglo XVIII». En ForTEA, J. I. GelaberT, J. E. (dirs.). La ciudad portuaria atlántica en la historia: siglos XVI-XIX. Santander: Autoridad Portuaria de Santander; Universidad de Cantabria, pp. 381-411.

${ }^{45}$ Catalogo de los libros, que se hallaran en la libreria de Dn. Manuel Espinosa de los Monteros. [Cádiz], 1760, A2r.

${ }^{46}$ VAN RossEM, S. (2008). «The bookshop of the Counter-Reformation revisited: the Verdussen company and the trade in catholic publications, Antwerp, 1585-1648». Quaerendo, 38, 4, pp. 306321. La correspondencia de Anisson en SABBE, M. (1923-1926). Briefwisseling van de gebroeders Verdussen, 1669-1672. Antwerpen.

${ }^{47}$ Catalogo de los libros, que se hallaran en la libreria de Dn. Manuel Espinosa de los Monteros. [Cádiz], 1760, A2v.

${ }^{48}$ VéLEZ, P. (1989). Eudald Pradell i la tipografia espanyola del segle XVIII. Barcelona: Gremi d'Indústries Gràfiques de Barcelona, pp. 31-32. Se ocupa del punzonista Pradell el estudio y catálogo de CORBETO, A. (2010). Especímenes tipográficos españoles: catalogación y estudio de las muestras de letras impresas hasta el año 1833. Madrid: Calambur, pp. 31-34. 
Figura 2: Catalogo de libros, que se venderàn en Cadiz ... de 1769 (Cádiz, 1769)

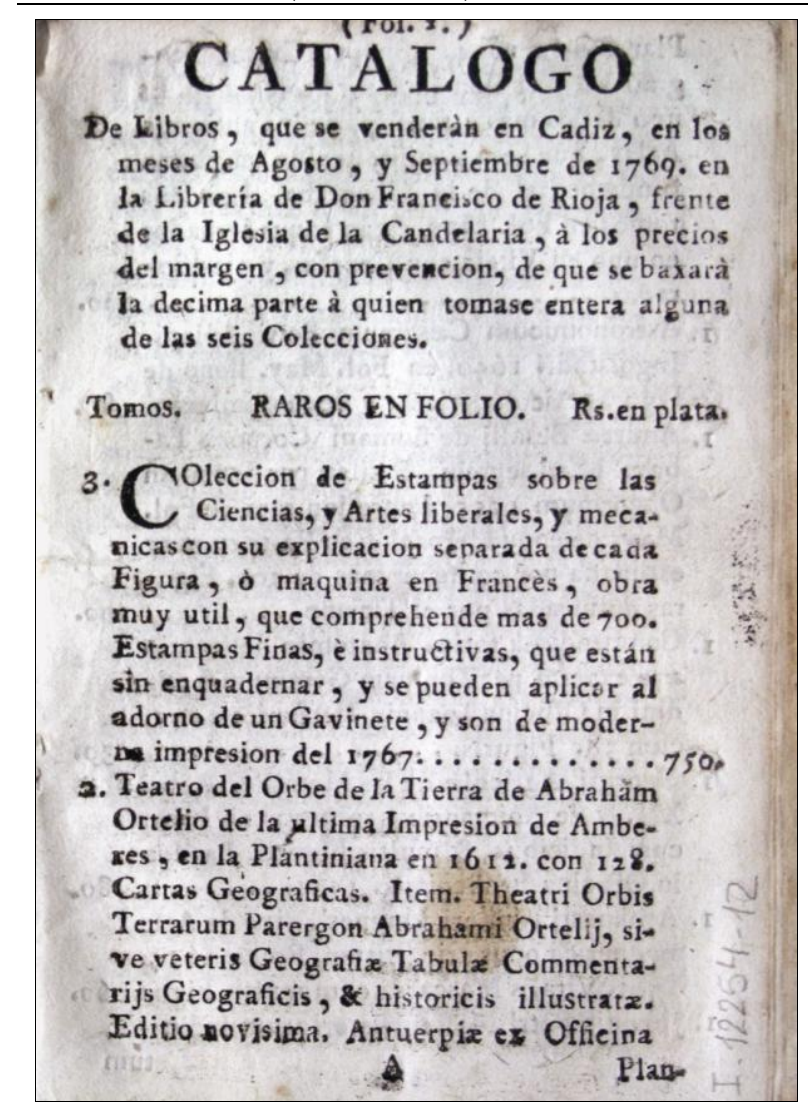

La estructura de los catálogos de venta estaba organizada según un orden de los saberes determinado, fijado en el momento de manera clara en las bibliografías al uso e imitado en estos modestos instrumentos de venta. Son numerosos los libreros que organizan los catálogos en cuatro grandes apartados (teología, jurisprudencia, medicina y cirugía, y humanidades) guiados por los posibles intereses de los compradores $^{49}$. La estructura de los catálogos sevillanos del siglo XVII es similar a la del catálogo impreso por Manuel Espinosa de los Monteros. La estructura es

49 SAN Román, Y. C. (2010). «Los catálogos de librería de las sociedades Anisson-Posuel y Arnaud-Borde conservados en la Biblioteca Histórica de la Universidad Complutense». Revista General de Información y Documentación, 20, pp. 353-389. 
idéntica, cuatripartita, y siguen el mismo orden de saberes situando a la teología en primer lugar para cerrar con los saberes "misceláneos", que recogen conocimientos humanísticos diversos. La diferencia entre ambos es la subdivisión realizada por Tómas López de Haro de las obras por formatos (teología en folio, en cuarto, "en doce, y en octavo", etc.), algo que Manuel Espinosa de los Monteros no mantiene, ya que prefiere ordenarlos alfabéticamente en cada grupo por el apellido del autor. En este sentido Manuel Espinosa de los Monteros construye un catálogo mejor estructurado, con separación de cada letra (de la A a la Z), jugando con los blancos al final de cada letra. Los catálogos de Tomás López de Haro eran simples listas, con escasos datos bibliográficos y con una descripción breve y sintética de los títulos. Manuel Espinosa de los Monteros ofrecía información detallada de cada título, de manera ordenada, y no contenía tantos errores ni erratas como los del siglo anterior, incluso contiene llamadas de véase tal autor o título, para de este modo remitir al lector al libro que busca.

El catálogo de venta de libros de Manuel Espinosa de los Monteros tenía una notable variedad de obras de teología $(53,3 \%)$, jurisprudencia $(18,4 \%)$ y humanidades $(18,9 \%)$, y en último lugar libros científicos $(9 \%)$, entre los que se incluyeron numerosas obras de medicina y cirugía. El elevado número de libros ligados al mundo de la religión y el derecho ofrecen una imagen de un listado de venta destinado a los estudiantes y profesores de los colegios y universidades, a los miembros del clero y de las estructuras jurídico-administrativas de la Corona, y a todos aquellos letrados que necesitan textos humanísticos latinos para su profesión o su recreo. El predominio de formatos en folio y cuarto (suman el 76,9\% del total de títulos) indica, igualmente, un libro destinado al estudio en gabinetes y bibliotecas, en contraste con las preferencias por los $12^{\circ}$ y otros formatos que se utilizan de manera cada vez más frecuente en el siglo XVIII para la literatura de entretenimiento y la difusión científica.

\section{MÁLAGA Y GRANADA, C. 1791}

A finales del siglo XVIII fue publicado un Catalogo de los libros latinos, franceses, italianos, y españoles que se hallan venales en Malaga, en la imprenta, y libreria de los Herederos de D. Francisco Martinez de Aguilar... y en Granada en la de Gabriel Martinez... [Málaga?, c. 1791]. En este caso la portada anunciaba los diferentes idiomas de las obras, siguiendo el esquema de los catálogos de Lyon o Ginebra que separaban por lenguas o territorios las $\mathrm{obras}^{50}$. La portada se

${ }^{50}$ CopPENS, C. (2003). «A census of printers' and booksellers' catalogues up to 1600», The Papers of the Bibliographical Society of America, 89, 4, pp. 447-455. Nuovo, A. (2003). Il commercio librario nell'Italia del Rinascimento. Milano: FrancoAngeli, pp. 228-242. 
convirtió en el mundo moderno en un elemento identificativo del punto de venta de los libros. El nombre del librero-editor resultaba esencial para dar a conocer la ubicación de la tienda o taller donde podían encontrarse los libros. Las portadas, y las tiendas, se complementaron con el catálogo que fue necesario para atraer lectores y fidelizar sus intereses, ofreciendo una imagen del librero como un aliado de Minerva, dispuesto a incontables esfuerzos para satisfacer a su público, atrayendo a los templos del saber de las librerías a literatos y letrados ${ }^{51}$.

El catálogo fue un medio de atraer al público, y los herederos de Francisco Martínez los utilizaron para lograr colocar una oferta variada de libros extranjeros, pero además utilizaron otros medios. La prensa periódica fue otro aliado de algunos libreros andaluces que utilizaron los anuncios para conseguir difundir las noticias sobre nuevos libros. Además, fue el medio idóneo para alcanzar repercusión en la Corte. En el siglo XVIII la aparición de anuncios en la prensa madrileña facilitó la herramienta que los libreros esperaban. Les ofrecía una amplísima difusión de los libros a la venta en los todos los rincones de la Monarquía. Los impresores y libreros al incluir el anuncio ofrecían la lista de lugares en los que los interesados podían comprarlos, o pedir por carta al librero, el libro en cuestión ${ }^{52}$. Estos breves anuncios facilitaban una radiografía del libro en circulación, dando cuenta de las novedades y cómo conseguirlas ${ }^{53}$. En el caso de los herederos de Francisco Martínez de Aguilar se observa este interés con gran claridad. En 1782 publicaron el Discurso historico-crítico de Fernando Ramírez de Luque y para alcanzar una cierta difusión de la edición se incluyó una breve noticia

51 La evolución de la imagen de la librería, y el sentido alegórico de muchas de las representaciones de marcas de impresor y representaciones pictóricas, puede seguirse en TAUBERT, S. (1966). Bibliopola: Bilder und Texte aus der Welt des Buchhandels. Hamburg: Hauswedell.

52 Morán OrTI, M. (coord.) (2000). La oferta literaria en Madrid, 1789-1833: un estudio cuantitativo de la cultura del libro. Madrid: Universidad Europea-CEES Ediciones. Dufour, G. (2003). «El Evangelio en triunfo o la historia de... la fabricación de un sueño editorial». Cuadernos dieciochistas, 4, pp. 67-77, analiza el rápido éxito de El Evangelio en triunfo gracias a los anuncios de librería de la Gaceta de Madrid, éxito fabricado con habilidad por el impresor Doblado. El papel de la prensa regional y local puede seguirse en el caso de Mallorca analizado por LLULL MARTí, A. (2006). Premsa i societat: una visió a través de la publicitat al primer diari de Mallorca (1808-1814). Palma: Documenta Balear.

53 GaZAPO ANDRAde, B. (1999). «Libros anunciados en el Diario de Madrid entre los años 1810 y 1819: evolución cuantitativa». Torre de los Lujanes, 39, pp. 67-86. Alonso SEOANE, Ma J. (2002). Narrativa de ficción y público en España: los anuncios en la Gaceta y el Diario de Madrid (18081819). Madrid: Universitas. También HARRIS, M. (2009). «Printed advertisements: some variations in their use around 1700». En Myers, R. HARRis, M. y MANDElbrote, G. (eds.). Books for sale: the advertising and promotion of print since the fifteenth century. New Castle: Oak Knoll Press; London: British Library, pp. 57-85. 
en la Gazeta de Madrid (6 de agosto de 1782) ${ }^{54}$, indicando los tres puntos de compra posibles, uno de ellos en Madrid en la librería de Manuel Barco, otro en Málaga y el tercero en Lucena "en la tienda de D. Antonio de Burgos", ya que el autor del libro era cura en esta ciudad ${ }^{55}$.

La intensa actividad desplegada por los herederos de Martínez de Aguilar, auténtica marca comercial que mantendrían durante años, revela un espíritu emprendedor y acorde con su tiempo. Esta casa comercial estuvo implicada en varios mecanismos de difusión y distribución de sus libros: publicando catálogos, incluyendo anuncios en las gacetas y participando en suscripciones. Este fue el caso de las Obras de Diego de Torres Villarroel, publicadas por la viuda de Ibarra en quince tomos, que contaba con una Lista de los señores subscriptores que incluía a los "los Herederos de Don Francisco Martínez de Aguilar, del Comercio de Málaga, por veinte y quatro exemplares" ${ }^{\text {56 }}$. Fue una librería activa e inquieta que logró ir mucho más lejos que otras librerías andaluzas.

\section{CÓRDOBA, C. 1793-1794}

En otros casos los catálogos ofrecían una imagen nítida de la especialización, bien al dedicarse a estampas "finas" para coleccionistas, orientarse a la publicidad editorial o buscar públicos específicos, bien lectores interesados en determinadas obras o vendedores (y revendedores). Este último caso se aprecia en uno de los catálogos más interesantes, e igualmente raro, publicado con el título de Lista del surtido de romances, relaciones, pasillos, coplas, historias, libros, y estampas en negro, e iluminadas, que en el dia tiene la Imprenta de Don Luis de Ramos y Coria, en Cordoba en la Plazuela de las Cañas [Córdoba: Luis de Ramos y Coria, c. 1793-1794]. En ciertos casos como en esta lista los ejemplares se vendían al por mayor, en forma de resmas o docenas. Esta distribución indica que se trataba de un catálogo de venta destinado a libreros, vendedores ambulantes, ciegos y todo tipo de mediadores, que luego venderían a otros agentes o al por menor los ejemplares, tanto en tiendas como en las calles, plazas y lugares concurridos de las ciudades y villas andaluzas. Los impresores, como es el caso de Luis de Ramos, publicaban

\footnotetext{
${ }^{54}$ Gazeta de Madrid del martes 6 de agosto de 1782. [Madrid]: En la Imprenta Real calle de las Carretas, [1782], p. 652.

55 RAMíREZ De LuQUE, F. (1782). Discurso historico-crítico sobre la precedencia y presidencia del Clero Secular. Malaga: en la imprenta de los herederos de D. Francisco Martinez de Aguilar. [22], 64, [2] p. ; $4^{\circ}$ CCPB000060016-4

56 TORRES Villarroel, D. de (1799). Vida, ascendencia, nacimiento, crianza y aventuras del doctor D. Diego de Torres Villarroel... Tomo XV. Madrid: En la imprenta de la viuda de Ibarra, p. 303.
} 
textos ya conocidos, que volvían a entrar en las prensas una y otra vez para satisfacer la demanda ${ }^{57}$. En el caso cordobés contamos con otro catálogo similar, ya del siglo XIX, en el caso de la Lista del surtido que en el dia tiene en su Imprenta Don Rafael Garcia Rodriguez, Calle de la Librería, Casa número 2. en Córdoba [Córdoba: Rafael García Rodríguez, c. 1826].

Estas ediciones locales cordobesas se distribuyeron tanto en librerías como en tiendas de mercería y mediante la venta ambulante. Los vendedores ambulantes iban en busca de algo de fortuna, llegando a los lugares concurridos como romerías y ferias, entrando en tabernas y posadas. Este fue el caso de Diego Hernández, un caso paradigmático de librero ocasional que viajaba a las zonas rurales en busca de clientela. Este vallisoletano se enroló como soldado, pero tuvo la mala fortuna de caer en manos de los corsarios que lo llevaron a Argel, tras tres años regresó "rescatado con su propio dinero" y se quedó en Sevilla. Con 26 años este antiguo soldado y cautivo quiso casarse con Bernarda María "de color membrillo cocho", y para justificar su parroquia y sus andares explicó que los últimos dos años: "los a estado en esta dicha [ciudad de Sevilla] sin hauer fecho ausencia della parroquiano de san Vicente y los dichos dos años del primer año cumplió en la yglesia en la dicha parroquia y este último año no se enpadronó por raçón de hauerse ydo a trabajar a la uilla de Montixo de su oficio de librero donde estuvo dos o tres meses

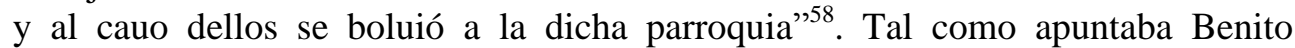
Jerónimo Feijoo al tratar de la diferencia entre los mercaderes de caudal y los buhoneros, unos "dentro de su lonja tienen los géneros para que allí los vayan a

${ }^{57}$ BOTREL, J.-F. (1997). «Literatura de cordel». En Diccionario de literatura popular española. Salamanca: Ediciones Colegio de España, pp. 179-185. CARo BAROJA, J. (1990). Ensayo sobre la literatura de cordel. Madrid: Istmo. También el trabajo de CASAS DELGADO, I. (2012). Romances con acento andaluz. El éxito de la prensa popular (1750-1850). Sevilla: Centro de Estudios Andaluces. El papel de los vendedores ambulantes en las ciudades europeas en Modigliani, A. (1998). Mercati, botteghe e spazi di commercio a Roma tra Medioevo ed età Moderna. Roma: Roma nel Rinascimento, pp. 109-116. Un caso similar al de Luis de Ramos es analizado por MolL, J. (19811982). «Un catálogo de pliegos sueltos de la imprenta de Agustín Laborda y Campo». Cuadernos de Bibliofilia, 8, pp. 57-66.

58 Archivo General del Arzobispado de Sevilla, Vicaría General, Expedientes Matrimoniales Ordinarios, leg., 2389. Expediente matrimonial de Diego Hernández y Bernarda María. Sevilla, 2 de septiembre de 1680. La movilidad de los libreros, y la dificultad para seguir sus actividades, puede seguirse en el análisis de Domingos, M. D. (1991). «Colporteurs ou livreiros?: acerca do comércio livreiro em Lisboa, 1727-1754». Rev. Biblioteca Nacional, 6, 1, pp. 109-142. 
buscar los que los hubieren menester; estos, se echan a cuestas su mísera tiendecita, y no hay plaza, no hay calle, no hay rincón donde no la expongan al público" ${ }^{99}$.

Los textos del catálogo de Luis de Ramos se producían en las mismas fechas en otras ciudades. Sutherland analiza el caso de El testamento del gallo de Cristóbal Bravo, un ciego natural de Córdoba y autor de esta "obra muy graciosa para reír"60. En pocos años, entre 1758 y 1766, se había editado en Valencia y Madrid, en tres ocasiones, y continuó con una renovada vida editorial durante décadas ${ }^{61}$. Esta notable facilidad de los textos para entrar en las prensas apunta a textos ajustados a las modalidades editoriales, remodelados cuando así lo requerían durante el proceso de composición, dependiendo de los tipos con los que contaba la imprenta o las xilografías con las que se adornaba, etc. El interés de Luis de Ramos por los romances, relaciones, "papeles", "historias", "novenas y otros libretes" y entremeses revela los principales apartados de la oferta: entretenimiento en prosa y verso, y devoción, esto último tanto por los títulos de vidas de santos como por las novenas y las estampas que el catálogo agrupaba por formato en "de a pliego", "de a medio pliego" y en octavo. Una buena parte de la producción recogida en el catálogo de Luis de Ramos se vendía a 45 reales la resma, únicamente las estampas tenían un precio mayor, de 66 reales, y los cuadernos de gramática y cuentas, de 60 reales. Una resma impresa se componía, aproximadamente, de unas veinte manos y cada mano de unos 24 o 25 pliegos. El hecho de que se vendieran en resmas indica que formaba parte de una cadena de distribución que repartía estas resmas en lotes más pequeños, generalmente en manos, para su reparto a diversos intermediarios. Esto puede verificarse, ya que la mano fue una unidad de reventa muy habitual, como demostró Botrel en el caso de José Cuervo. Este ciego compró en 1731 cuatro manos de un impreso, en su caso una sátira, y revendió una mano a Pedro Contreras y dos a Gregorio Álvarez ${ }^{62}$.

59 Feijoo y Montenegro, B. J. (1736). Theatro critico universal o Discursos varios en todo genero de materias para desengaño de errores comunes ... tomo septimo. En Madrid: en la imprenta de los herederos de Francisco de el Hierro, p. 265.

${ }^{60}$ BRAVO, C. El testamento del gallo, obra muy graciosa para reir, y pasar tiempo. En Madrid: en la imprenta y libreria de Andres de Sotos, [s.a.]. Ed. digital de la Biblioteca Valencia accesible en: http://bivaldi.gva.es/bivaldioai/consulta/registro.cmd?id=5533 [Consultado: 21-08-2012].

${ }^{61}$ Sutherland, M. (1991). Mass culture in the age of Enlightenment. The blindman's ballads of Eighteenth-Century Spain. New York: Peter Lang, pp. 22-23.

62 Botrel, J.-F. (1993). Libros, prensa y lectura en la España del siglo XIX. [Salamanca]: Fundación Germán Sánchez Ruipérez; Pirámide, p. 113. Los cambios a finales del Antiguo Régimen en MARTíneZ MARTín, J. A. (2003). «Las transformaciones editoriales y la circulación de libros». En Orígenes culturales de la sociedad liberal: (España, siglo XIX). Madrid: Biblioteca Nueva, pp. 37-64. 
Si analizamos uno de estos impresos populares veremos que podían contar con un número limitado de páginas $\mathrm{y}$, por lo tanto, su coste de producción era reducido y podía distribuirse por canales que pusieran a la venta un producto de consumo para un público amplio. La Curiosa jácara que declara la vida y muerte del churripampli ${ }^{63}$, un impreso en $4^{\circ}$ de 4 páginas, se imprimió en medio pliego, con una imposición de la mitad de las páginas de un cuaderno normal. Tal como explica Riffaud el pliego impreso en el blanco con las cuatro páginas se gira sobre sí mismo para la impresión de la retiración, de este modo en el pliego se imprimen dos mitades idénticas, se corta el pliego en dos y se pliega una vez, obteniendo de una sola forma compuesta en cuarto dos ejemplares idénticos por pliego. ${ }^{64} \mathrm{En}$ otros casos eran de 8 páginas, o bien dos partes de la misma relación o romance, cada una de 4 páginas, que resultaba una unidad de medida habitual para este tipo de impresos. Tal como el bibliógrafo Wilson indicaba "spanish printers early discovered that a single quarto gathering made a cheap book" $"$.

En el caso de Luis de Ramos la publicación del catálogo resultó un medio de difusión de los textos "que en el día tiene" su imprenta, ofreciendo una completa panorámica de la oferta. En otros casos los impresores-editores ofrecían información sobre estos materiales en pies de imprenta y en las obras publicadas, como fue el caso, ya del siglo XIX, del impresor Antonio Álvarez Robles, que desde Baza anunciaba a través de sus impresos que en su imprenta "se hallará un buen surtido de romances y relaciones a precios muy arreglados" ${ }^{\prime 66}$ o la edición de una Espinela (1833) en Lucena que indica el éxito de estos textos a nivel local, con imprentas que abastecen áreas más restringidas ${ }^{67}$.

${ }^{63}$ Curiosa jácara que declara la vida y muerte del churripampli. Reimpreso en Cordoba: en la imprenta de D. Luis de Ramos, Plazuela de las Cañas, [s.a.]. Ed. digital de la Universidad de Sevilla accesible en: http://fondosdigitales.us.es/fondos/libros/560/ [Consultado: 21-08-2012].

${ }^{64}$ RiffaUd, A. (2011). Une archéologie du livre français moderne. Genève: Droz, pp. 63-64.

${ }^{65}$ WILSON, E. M. (1955). «Quevedo for the masses». Atlante, 3, pp. 151-166 (cita de la p. 151). Un ejemplo de composición de dos partes de un romance con $4+4 \mathrm{p}$. en un formato $4^{\circ}$ en el caso del Romance del feliz hallazgo y milagro del SS. Christo de Torrijos. Primera parte. En Córdoba: en la imprenta de D. Luis de Ramos, Plazuela de las Cañas, donde se hallará todo género de surtimiento, s.a. 4 p. A continuación el Curioso romance en que se refieren algunos de los milagros que ha obrado el Santisimo Cristo de Torrijos. Segunda parte. En Córdoba: En la Imprenta de D. Luis Ramos, Plazuela de las Cañas, s.a. 4 p.

${ }^{66}$ Botrel, J.-F. (1983). Op. cit., p. 114, n. 40. Las nuevas estrategias de venta son analizados por Morán ORTí, M. (2003). «Librería e Imprenta en Madrid a comienzos del siglo XIX». Torre de los Lujanes, 49, pp.67-94.

${ }^{67}$ Espinela. Lucena: Imprenta Nueva, 1833. El impreso de [4] p. lleva el no 33. 
En ocasiones fueron las guías de viajeros y los anuarios los que comenzaron a anunciar a los libreros. Este fue el caso de los gaditanos Verdugo, Morillas y compañía que se incluyeron en el Anuario general del comercio, de la industria y de las profesiones $(1863)^{68}$. Algunos aprovechaban estos breves anuncios para ofrecer sus catálogos, como hizo el librero barcelonés Joan Oliveres, que indicaba que "remite el catálogo de su librería, que contiene más de 4.000 títulos, a los señores que lo pidan"69. Aunque tardaría un tiempo en producirse una identificación del catálogo con una línea editorial tal como hoy día ocurre, aunque algunos casos del siglo XIX, como el de Cabrerizo en Valencia apuntaban un modelo que sería imitado por otros editores. ${ }^{70}$

\section{MÁLAGA, SIGLO XVIII}

Las estampas están presentes en al menos tres modalidades diferenciadas de catálogos. a) Venta de estampas como parte de la estrategia de venta de menudencias impresas. Estos catálogos incluyen estampas populares y anuncian una variada gama de impresos. Esto es lo que sucedía en el caso de del catálogo de Luis de Ramos que acabamos de ver, que incluía un apartado de estampas. b) Las estrategias de los libreros que anuncian la venta de estampas junto a libros de surtido. Las estampas aparecen en los catálogos de venta de libros, conjuntamente con estos y pueden venderse junto a juegos de la oca, librillos educativos y productos de papelería. Las estampas fueron comercializadas en toda una amplia gama de establecimientos, y estos catálogos permitían la distribución a otros libreros, pero también a todo tipo de tiendas (mercerías, tiendas de comestibles, etc.) y a diversos intermediarios (buhoneros, ciegos y otros) que ocasionalmente abastecieron las zonas rurales. c) Algunos libreros anunciaban estampas "finas" y buscaban una clientela selecta y con mayor poder adquisitivo. Los catálogos de venta incluían estas estampas junto a libros o separadamente en catálogos exclusivamente de estampas, que son mas raros en el caso español, aunque como veremos los libreros malagueños decidieron dar salida a las "estampas finas" vendiéndolas en su tienda en pleno centro de Málaga. Lo habitual es encontrarnos algunas referencias a estampas "finas" en algún apartado. Aunque algunos editores como Antonio de Sancha llegaron a anunciar la preparación de catálogos de venta

68 Marty CABAllero, L. (1863). Anuario general del comercio, de la industria y de las profesiones. Madrid: Oficinas del Anuario, pp. 671-672.

${ }^{69}$ Marty Caballero, L. (1863). Op. cit., p. 670.

${ }^{70}$ EsPinÓs I QUERO, A. (2005). «La colección de novelas del editor Cabrerizo (I)». Hibris, 25, pp. 30-39. 
de estampas "exquisitas", con la intención de atraer el interés de clientes que podían interesarse por las reproducciones de obras artísticas ${ }^{71}$.

En los catálogos que incorporaban estampas suele indicarse de manera muy genérica sus características (si estaban iluminadas o no, si se vendían por docenas o al por menor), sin precisar generalmente la autoría, el título, o las dimensiones. En muchos casos los catálogos ofrecían información básica sobre las estampas indicando si era un retrato, un paisaje o una reproducción de obras de arte. En cualquier caso las descripciones son breves, coincidimos con el análisis de Selbach de los catálogos franceses que indica que "ces documents restent généralement très vagues"72. Es el caso del Surtido de estampas finas que se hallan en Málaga en la imprenta y libreria de Iglesias y Martinez calle de la Cinteria [s.l.: s.n., s.a.]. Fue impreso en una sola hoja en un formato en cuarto, idóneo para distribuirse como hoja volandera. En este caso Rodríguez-Moñino referenció el catálogo, pero no hemos podido localizar ejemplares, lo que no debe hacernos dudar de la existencia de esta edición ${ }^{73}$. En este caso todo el catálogo se dedicaba a la venta de surtido, un término revelador que indica la existencia de lotes variados, temáticamente y en formato.

\section{DEL SURTIDO A LA ESPECIALIZACIÓN}

En los catálogos de libros se observa una paulatina especialización, en gran medida desde comienzos del XIX, en torno a los libros raros, obras de bibliofilia, o bien ofreciendo algunas temáticas (por el tipo de libros o intereses de los lectores $)^{74}$.

${ }^{71}$ Catalogo de los libros que se hallan en la libreria de Sancha, calle del Lobo. Madrid, 1806, incluye un apartado de libros de estampas, pp. 180-182. Biblioteca Nacional de España, U/10799. Algunos editores como Remondini llegaron a publicar catálogos especializados en la venta de estampas, entre 1772 y 1793 se contabilizan seis catálogos "delle stampe in rame, in legno" o "delle stampe incise". INFELISE, M. MARINI, P. (1990). Remondini. Un editore del settecento. Milano: Electa, pp. 80-81. La importancia de los anuncios también merece ser destacada, ver PoRTús, J. VeGA, J. (1998). La estampa religiosa en la España del Antiguo Régimen. Madrid: Fundación Universitaria Española, pp. 555-568 (apéndice III: anuncios de estampas insertados en la prensa de Madrid).

72 SelbaCh, V. (2006). «La place de l'antique dans les collections d'estampes $\left(\mathrm{XVI}^{\mathrm{e}}-\mathrm{XVIII}^{\mathrm{e}}\right.$ siècle)». En VolpiLHAC-Auger, C. (dir.). D'une Antiquité a l'autre: la littérature antique classique dans les bibliothèques $d u X V^{e}$ au XIX $X^{e}$ siècle. Lyon: ENS Éditions, p. 91.

${ }^{73}$ RodrígueZ MOÑINO (1966). Op. cit., p. 42.

74 ANDRÉS, G. DE (1993). «El Hispanista Obadiah Rich y la almoneda de libros españoles en Londres en 1824». Boletín de la Real Academia de la Historia, 190, pp. 283-311. 
Estos catálogos especializados son poco habituales en la edad moderna en Andalucía, ya que el mercado de coleccionistas tenían un potencial interesante pero limitado, y los catálogos con libros de este tipo fueron más habituales en centros librarios como París o Londres en los que el mercado anticuario contaba con una densa red de intermediarios y agentes que compraban y vendían en toda Europa. ${ }^{75}$ Lo que podemos observar son referencias en anuncios y en catálogos a libros a piezas de valor bibliográfico. Este fue el caso de un ejemplar de la Biblia políglota complutense que se anotaba en uno los catálogos de la librería madrileña de Matute pero que se hallaba a la venta en "Cádiz en la librería de don Esteban Picardo, calle de la Carne, núm 186"76. Estos casos indican que determinadas piezas buscaban clientela a través de la red tejida en torno a la Corte y a los libreros con más corresponsales. Las piezas más codiciadas por su rareza podían ser objeto de una dilatada búsqueda, en gran medida a raíz de la llegada de viajeros europeos, que despertaron un notable interés por las piezas españolas entre los coleccionistas europeos $^{77}$. El bibliófilo Sergio Sobolevsky visitó España y llegó a publicar dos cartas con sus impresiones en el Journal de l'amateur de livres, en las que informaba del impacto de la Desamortización en el mercado del libro, ya que "la dispersión de las bibliotecas del clero alimentó durante muchos años al comercio de libros viejos; casi todos los que valían la pena, o por su rareza, o por su conservación, pasaron poco a poco al extranjero" ${ }^{\text {78. }}$. Algunos de estos impresos pasaron a los catálogos de los libreros de París, Leipzig o Londres. La historia de la venta de estos libros en los catálogos europeos ayudaría a entender la circulación de determinadas piezas (algunas excepcionales) que empezaron a interesar también a las grandes bibliotecas nacionales, que durante el siglo XIX ampliaron sus colecciones hispánicas comprando por catálogo a libreros especializados ${ }^{79}$.

\section{CONCLUSIONES}

Como hemos visto en estos casos analizados, una gavilla de doce catálogos y anuncios, los libreros andaluces lograron incorporar nuevas técnicas de publicidad

\footnotetext{
${ }^{75}$ Moureau, F. (2006). La plume et le plomb. Espaces de l'imprimé et du manuscrit au siècle des Lumières. Paris: PUPS, pp. 103-129.

${ }^{76}$ RodrígUeZ MOÑINO (1966). Op. cit., p. 188.

77 BAS MarTín, N. (2002). «Libros raros y curiosos españoles en un catálogo francés del siglo XVIII». Pliegos de Bibliofilia, 18, pp. 21-44.

${ }^{78}$ Sobolevsky, S. (1951). Bibliofilia romántica española (1850). Trad. de Joaquín de Val. Notas de A. Rodríguez-Moñino. Valencia: Editorial Castalia, p. 67.

${ }^{79}$ WEST, G. (1997-1998). «Libros religiosos coloniales de la British Library: libros impresos en México, Perú, Chile, Cuba, Ecuador y Guatemala, 1543/4-1800». REDIAL: revista europea de información y documentación sobre América Latina, 8-9, pp. 69-92.
} 
del libro. Los catálogos les proporcionaron un medio de contactar con un público lector que podía conocer (y descubrir) títulos a la venta de las librerías. Los libreros intentaron superar la limitada capacidad de difusión de noticias mediante carteles o los propios escaparates, con la finalidad de ampliar el radio de acción de la tienda o el taller. Esto adquirió un mayor sentido en las ventas de libros en los territorios de Nueva España, la publicación de cinco catálogos entre los años 1680-1689 estuvo estrechamente ligada a las estrategias de los libreros sevillanos. Es, con bastante probabilidad, el mismo caso de la Memoria de libros a la venta en Buenos Aires, ya que fue usual el paso de factores de los libreros sevillanos (y gaditanos) que pasaron con libros para la venta en los territorios de la Corona española en América. Estos catálogos tienen varios elementos en común, el más evidente es que se imprimieron para dar a conocer al otro lado del Atlántico los libros que podían encontrarse a la venta en los cajones embarcados. Estos títulos se enviaron en los navíos de la Carrera de Indias y, de este modo, los catálogos servían para anunciar las novedades recién enviadas y promocionar los libros.

En los preliminares del catálogo de Manuel Espinosa de los Monteros se insiste en su capacidad para conseguir los libros que se le piden, convirtiendo su librería en centro de referencia. La oferta de buena parte de los catálogos analizada se centra en la venta de obras surtidas, tanto castellanas como latinas (y algunas en griego), pero también encontramos catálogos especializados en libros latinos (muchos procedentes de prensas extranjeras) de Manuel Espinosa de los Monteros o el de los herederos de Francisco Martínez de Aguilar.

Aunque también hay imprentas, como la de Luis Ramos, que ofrecía un abanico amplio de textos de entretenimiento y devoción salidos de sus prensas, realizados en Córdoba y destinado a una distribución popular. En este caso el catálogo estaba destinado a libreros e impresores, así como a ciegos e intermediarios diversos, que compraban al por mayor, por manos o docenas, para luego revender en los negocios minoristas y al público.

De este modo cada catálogo responde a diferentes modalidades de negocio, bien de larga distancia al otro lado del Atlántico, pero también buscando nuevas clientelas locales o regionales en Andalucía. La mejora de las comunicaciones en el siglo XVIII y la consolidación de las redes postales también facilitaron la circulación de las noticias (y los libros). Estos doce catálogos son una muestra de los diferentes destinatarios finales del catálogo, se observa la publicación de catálogos destinados al consumidor final, pero también la distribución a través de toda una cadena de compra-venta en la que intervienen mediadores culturales del impreso que logran que los textos de las prensas lleguen al público. 


\section{APÉNDICE: CATÁlogos DE VENTA PUBLICADOS EN ANDALUCÍA (1680-1800).}

[1] CATAlogus | LIBRORUM, | ô | Memoria de Libros de todo genero de Facul- $\mid$ tades, que se venden en Casa $\mid$ DE | DIEGO CRANZE |EN ESTA CIUDAD. | [Grab. xil. con las Santas Justa y Rufina y La Giralda] | Por DIEGO CRANZE, Año 1680. [Sevilla: Tomás López de Haro?], 1680. 9 p.

México, D.F. Archivo General de la Nación. Inquisición, vol. 667, f. 348r-352r.

[2] CATALOGO, | O MEMORIA DE LIBROS, | DE TODAS FACULTADES. | Se venden en casa del Capitan | Fernando Romero. | Con licencia de la Santa Inquisicion. | Para vender en Vera Cruz, y la Puebla $\mid$ de los Angeles, y la Ciudad | de Mexico. | [Grab. xil. de un jarrón de flores] |EN SEVILLA. 1682. | [Filete] | En la Oficina de Tomas Lopez de Haro, | Impressor, y Mercader de libros. 23 p.

México, D.F. Archivo General de la Nación. Inquisición, vol. 657, f. 496r-507r.

[3] CATAlOGO | SEGVNDO, | O MEMORIA DE LIBROS, | DE TODAS FACVLTADES; | Que se venden en casa del Capitan |Fernando Romero. | Con licencia de la Santa Inquisicion. | Para vender en Vera-Cruz, y en la Puebla $\mid$ de los Angeles, y en la Ciudad $\mid$ de Mexico. | [Grab. xil. de un jarrón de flores] $\mid$ EN SEVILLA. 1683. | [Filete] | En la Oficina de Tomas Lopez de Haro, | Impressor, y Mercader de Libros. [8] p.

México, D.F. Archivo General de la Nación. Inquisición, vol. 657, f. 508r-511v.

[4] CATAlogo, | O MEMORIA DE LIBROS, | DE TODAS FACVLTADES. | Se venden en casa del Capitan | D. Fernando Romero. | Con licencia del Tribunal de la Santa Inquisicion. I Para vender en la Verz-Cruz, en la Puebla | de los Angeles, y en la Ciudad de | Mexico. | [Colofón:] EN SEVILLA. | [filete] | Por Thomas Lopez de Haro, Impres- | sor, y Mercader de Libros, en las | siete Rebueltas, junto a la| Imagen, año 1687. [17] p.

México, D.F. Archivo General de la Nación. Inquisición,1086, exp. 11, f. 254r263 r.

[5] CATALOGO, | O MEMORIA DE LIBROS, | DE TODAS FACVLTADES. | Se venden en casa del Capitan Don | Diego Ybañez. | Con licencia del Tribunal de ls Sa[n]ta Inquisicion. | Para vender en las Indias. [Sevilla: Tomás López de Haro?, 1689]. [11] p.

Sevilla. Archivo General de Indias. Contratación, 674.

RODRíGUEZ MoÑIno (1966). Historia de los catálogos, p. 3. TORRE REVELlo, J. (1929). «Un catálogo impreso de libros para vender en las Indias Occidentales en 
el siglo XVII». Boletín del Instituto de Investigaciones Históricas, VII, 40, pp. 233-253.

[6] [cruz] $\mid$ CATALOGO | DE LOS LIBROS, | QUE SE HALLARAN | EN LA LIBRERIA $\mid$ DE $\mid$ D. ${ }^{\mathrm{N}}$ MANUEL ESPINOSA $\mid$ DE LOS MONTEROS, | IMPRESSOR R. ${ }^{\mathrm{L}}$ DE MARINA, | EN LA CIUDAD | DE CADIZ, | CALLE DE S. FRANCISCO. | AÑO DE 1760.118 p.

Puebla de Zaragoza. Biblioteca Palafoxiana, 40085-A.

[7] [Catálogo de los libros en romance que se hallarán en la librería de D. Manuel Espinosa de los Monteros]. [Cádiz: Manuel Espinosa de los Monteros, c. 1760].

No se conocen ejemplares. La única referencia segura de la existencia de este catálogo proviene del $\mathrm{n}^{\circ} 6$ en el que en una "nota" se indica que "con el mismo méthodo, claridad, y distincion de authores y materias [...] están impressas en nuestro idioma español, se da al público otro Catálogo".

[8] CATAlogo $\mid$ De libros, que se venderàn en Cadiz, en los $\mid$ meses de Agosto, y Septiembre de 1769. en la Librería de Don Francisco de Rioja, frente | de la Iglesia de la Candelaria, à los precios | del margen, con prevencion, de que se baxarà $\mid$ la decima parte à quien tomase entera alguna $\mid$ de las seis Colecciones. [Cádiz: s.n., 1769]. 31 p.

Londres. British Library, General Reference Collection, 821.c.23.

Madrid. Biblioteca Lázaro Galdiano M 1-2-30(12).

RODRÍGUEZ MOÑINO (1966). Historia de los catálogos, p. 86.

[9] Catalogo de los libros latinos, franceses, italianos, y españoles que se hallan venales en Malaga, en la imprenta, y libreria de los Herederos de D. Francisco Martinez de Aguilar ... y en Granada en la de Gabriel Martinez ... [Málaga?: s.n., c. 1791]. 93 p.

Madrid. Real Academia Española, RM-2498.

RODRÍGUEZ MOÑINO (1966). Historia de los catálogos, p. 79.

[10] Surtido de estampas finas que se hallan en Málaga en la imprenta y libreria de Iglesias y Martinez calle de la Cinteria. [Málaga?: s.n., finales del XVIII]. [1] h.

RODRÍGUEZ MOÑINO (1966). Historia de los catálogos, p. 42.

[11] Memoria de libros que se hallarán en la Ciudad de Buenos-Ayres en poder de D. [S.l.: s.n., s.a.]. 23 p.

MEDINA, J. T. (1968). Biblioteca hispano-americana: 1493-1810. Amsterdam: N. Israel, t. VI, núm. 7242. Indica Medina que "parece del último tercio del siglo XVIII" y que se trata de una "impresión peninsular". Lo que podría indicar un 
impreso gaditano o sevillano relacionado con el tráfico comercial de libros a Buenos Aires. J. TORRE REVELlo (1991). El libro, la imprenta y el periodismo en América durante la dominicación española [1940]. México, p. 124, n. 3, recogía estos datos de Medina indicando que era "prueba que los libreros peninsulares estampaban los catálogos de las obras que destinaban a la venta en nuestra capital, dejando en blanco el nombre del representante, el que se le agregaba después a mano". Los investigadores siguen citándolo sin que haya sido posible, desde el hallazgo de Medina, encontrar ningún ejemplar, por ejemplo, lo cita PARADA, A. E. (2007). «Los itinerarios lectores de un librero cultural: el Catálogo de la librería argentina de Marcos Sastre (1835)». Boletín de la Academia Argentina de Letras, 289-290, p. 218.

[12] Lista del surtido de romances, relaciones, pasillos, coplas, historias, libros, y estampas en negro, e iluminadas, que en el dia tiene la Imprenta de Don Luis de Ramos y Coria, en Cordoba en la Plazuela de las Cañas, con los precios de todo. [Córdoba: Luis de Ramos y Coria, c. 1793-1794]. [6] h.

Se ocupo del análisis de este catálogo CARo BAROJA (1990). Ensayo, p. 71. RODRíGUEZ MOÑINO (1966). Historia de los catálogos, p. 85, según este autor "Valdenebro, La imprenta en Córdoba, cita el presente opúsculo, asignándole la fecha de 1796. El ejemplar que tenemos a la vista lleva una nota de letra contemporánea, que dice: «La Revisi, en 22 de febrero de 1794 años, me costó la Carta 13 quartos»”. PALAU 138855. VALDENEBRO Y CisNeros, J. M ${ }^{\mathrm{a}}$ (1900). La imprenta en Córdoba. Ensayo bibliográfico. Madrid: Sucesores de Rivadeneyra, p. 552 (indica que el impreso pertenecía al Duque de T'Serclaes), incluye en las entradas 1665-1964 las "hojas volantes" impresas por Luis de Ramos. 